\title{
Coverillustration
}

\section{In the eye of the beholder}

f fees were charged for the sight of a rainbow, Cambridge University should receive a commission. Our understanding of the rainbow's mysteries came principally from the faculty of Cambridge, including professors Isaac Newton, Thomas Young, George Airy, Richard Potter, and Lord Rayleigh. Each of these men provided important steps towards our current understanding of the family of bows, which includes the rainbow as its most famous member.

Early references to the rainbow are made in the Bible where it is written that Noah was given the rainbow as a gift and a covenant that the earth would never again be destroyed by water. Homer, in the Iliad, describes Iris as the goddess of the rainbow. Iris was regarded as a messenger, or bridge, between the gods, especially when they intended discord.

The Greeks began the scientific investigation into the rainbow, and claim several important advances. Alexander of Aphrodisias was the first to document the dark strip between the two arcs of the double bow (visible on the cover), and the phenomenon bears his name today as Alexander's phenomenon. Aristotle, about $\mathrm{AD} 322$, wrote that tiny mirrors in the clouds were responsible for the reflected light that created the bow. He stated that the colours were caused by a weakening of the light. His explanation, which held sway for 1500 years, was wrong.

Other men began to understand and come closer to the correct explanation but were generally ignored until the 17th century. At that time, Rene Descartes, with help from Harriot, Snell, Kepler, and others, correctly described the two refractions and one reflection from each droplet that created the geometry of the first and second bow, but he could not explain the colours.

Newton, born at Woolsthorpe Manor, illustrated on this month's cover, correctly described the refraction of light that would create the colours of the bow. Newton was also most instrumental in the understanding of the rainbow with his creation of the calculus as a branch of mathematics. With Newton's calculus, Sir Edmund Halley (of comet fame) calculated the third and fourth order bows as being around the sun rather than being in the antisolar horizon, as are the first and second order bows.

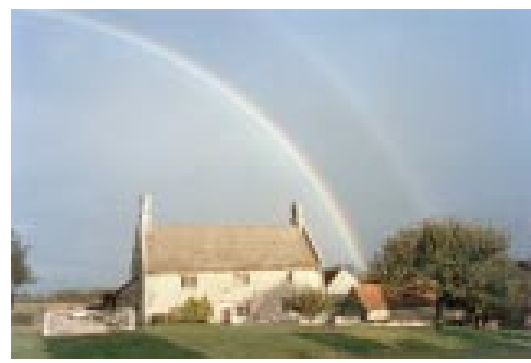

In the early 1800s, Thomas Young, educated at Cambridge, explained the supernumerary bows that can frequently be seen within the primary rainbow. He championed the wave theory of light to explain these interference bows although this was at odds with the corpuscular theory of light put forth by the revered Newton, and it took others such as Fresnel and Richard Potter (again of Cambridge) to convince the world of physics that Young was correct.

George Airy, professor of astronomy at Cambridge, further explained the interference bows, the mathematics of diffraction, and took the explanation of the family of bows to a new mathematical level when he stated that light passing through the raindrop was a caustic. A caustic is a curved wavefront such as one would see when light is reflected from the surface of a smooth, curved silver ring. Airy further extended the understanding of the wave theory of light and thought the explanation of the rainbow complete.

But the $38^{\circ}$ bow, often known as a fog bow, eluded Airy's explanation. It remained for Lord Rayleigh to alter Airy's theory to explain bows from extremely small droplets of water. James Maxwell, of colour wheel fame, would later propose that light was a form of mechanical vibration providing the basis for the electromagnetic wave theory and thus unifying existing concepts.

Others, including Poincare, Watson and, later, Feynman, would devise the quantum electrodynamic theory of light to include the angular momentum of photons, taking the explanation of the rainbow to yet another mathematical level beyond the scope of this essay.

But this does not give us the rainbow. Instead, it provides us with energy waves of a certain wavelength at a certain angle, but not the rainbow. The beautiful colours that create the rainbow are only "seen" by the brain although excitation occurs at the photoreceptors.

Part of our understanding of perception comes from Thomas Young who, in a Bakerian Lecture, correctly predicted the trichromacy theory of vision and three photoreceptors as the tools to achieve colour perception.

Helmholtz and Maxwell further expanded the theory of colour vision, but did not discuss perception. In fact, the human eye/brain can distinguish 8000 colours at a single luminance and a total of eight million shades and tints. Visual processing does all this and the brain must make many assumptions. As a result we are blessed with colour constancy, that feature which allows us to perceive a lemon as a lemon in almost any light level. We still see a lemon in different light even though the photometric measurement of the wavelength given off by the lemon in bright noontime sun is vastly different from the wavelength of light given off by the same lemon in twilight. Yet, we don't know how the brain does this.

The 17th century with Descartes, Newton, and others, and the 19th century with Young, Airy, Maxwell, Helmholtz, Hertz, and others were important centuries in the understanding of the rainbow. Perhaps the 21 st century is the time for another major breakthrough in the true understanding of the family of bows, and now the horizon is perception.

I R Schwab,

University of California, Davis, Department of Ophthalmology, 4860 "Y" Street, Suite 2400 Sacramento, CA 95817, USA; irschwab@ucdavis.edu

The sensational cover photograph of a double rainbow over Woolsthorpe Manor, Sir Isaac Newton's birthplace, was taken by Roy L Bishop of Nova Scotia. He graciously consented to our publication of this photograph. 